\title{
Vaginal Dryness
}

National Cancer Institute

\section{Source}

National Cancer Institute. Vaginal Dryness. NCI Thesaurus. Code C78699.

An uncomfortable feeling of itching and burning in the vaginal opening resulting from inadequate vaginal lubrication. It is commonly seen during and after menopause, childbirth, or stressful conditions. It results in painful intercourse. 